\title{
DNA fingerprinting to distinguish the coconut type, San Ramon
}

\author{
C.K. Bandaranayake ${ }^{1}$, W.B.S. Fernando, A. Fernando and N. Herath
}

\begin{abstract}
San Ramon, an introduced type of coconut from Philippines, has long been in Sri Lanka. San Ramon has the advantage of producing high copra, high oil, and high-quality timber and also seemed to be less variable for bunch characters. In addition, it is a type of coconut having an ability to withstand long droughts and also coconut mites. Due to these outstanding beneficial characters, San Ramon has been used as a parent for effecting various crosses to transmit the drought tolerance nature and high copra outturn, to the offspring. The physical structure of San Ramon palms is much comparable to tall type coconuts though there are some specific characters predominantly seen in favourable environments. On top of these circumstances, it is not easy to separate San Ramon from other Talls and virtually impossible to distinguish pure San Ramon from San Ramon crosses by means of only morphological markers. Therefore, a molecular finger-printing method was attempted to distinguish pure San Ramon using already developed 10 coconut SSR primers. The results indicate the possibility of distinguishing pure San Ramon from its crosses with the help of 2 coconut SSR primers, CNZ6 and CNZ44.
\end{abstract}

Key words: Coconut, DNA fingerprinting, molecular marker, San Ramon, SSR primers.

\footnotetext{
${ }^{1}$ Genetics and Plant Breeding Division, Coconut Research Institute, Lunuwila, Sri Lanka. E-mail: bandaranayakeck2000@yahoo.com
} 


\section{Introduction}

DNA fingerprinting of plants or plant genotyping is a technology that has been established and is primed for very widespread practical applications such as, identification of plants in commerce, plant breeding and research. Our interest as plant breeders and molecular biologists is to identify plants accurately to use in crossing programmes and also to test hybridity. Plant breeding applications range from marker assisted selection (MAS) to the confirmation of identity of parents and progeny in breeding populations.

The coconut (Cocos nucifera) is called the tree of life because it provides humans with such a wide range of essential products; food and drink (coconut milk, coconut cream, desiccated coconut, tender coconut water, coconut arrack, coconut vinegar, coconut honey and coconut jaggery); materials for housing, fuel and many industrial uses such as shell charcoal, activated carbon, shell powder, shell handicrafts, furniture, coir products, soaps, and cosmetic industries etc. It can be taken as a treasure for people in many tropical countries considering it as a caloric supplier, foreign exchange earner and also a crop with a multitude of uses for income generation for poor farmers. It plays a unique role in the diets of mankind because it is the source of important physiologically functional components found in the fat part of whole coconut and of desiccated coconut as well as in the extracted coconut oil. The medicinal uses of coconuts, antibacterial, anti-viral and anti-fungal activities due to lauric acid and capric acid, are many and varied (Enig, 1999; Dayrit, 2000). Also it has been shown that natural coconut fat in the diet leads to a normalization of body lipids, protects against alcohol damage to the liver and improves the immune system's anti-inflammatory response (Enig, 2001).

San Ramon, an introduced type of coconut from Philippines, has long been in Sri Lanka (Fernando, 1987). San Ramon nuts are very large and round with a thick kernel and the underside of the dehusked nuts is flat. The physical structure of San Ramon palms is much alike to tall type coconuts. Inherently, they are huge erect tall trees with stout trunks and massive boles under a favourable environment. But the above description of the physical structure of the palm could be changed under different soil and climatic conditions. Therefore, it is not very easy to separate San Ramon from Tall and totally impossible to distinguish pure San Ramon from San Ramon crosses.

San Ramon has the advantage of producing high copra with a low cost of production since it has high copra content of 350-400 g per nut while in other coconut varieties it varies from 210-225 g (Fernando, 1987). San Ramon inherits the potential of producing $51 \%$ more copra per nut than Sri Lanka Tall palms and $50 \%$ more copra per nut than the improved tall, CRIC60. Preliminary investigations have shown that the oil extraction efficiency of copra is much higher than Sri Lanka Tall (Fernando, 1999). Another special feature of San Ramon is its drought tolerance. The extent of stress tolerance in San Ramon was investigated by Ranasinghe (1989) and reported that the levels of total soluble sugars, starch content and proline content were significantly higher both in San Ramon and its crosses. Accumulation of proline under water deficit conditions has been shown to be a sensitive indicator of drought tolerance in annual crops (Singh et al., 1973), and Jayasekara et al., (1983) confirmed this phenomenon for coconut since higher concentrations of proline accumulation was observed during dry conditions for genotypes identified as stable when assessed for drought sensitive physiological parameters.

In addition to that, it seemed to be less mite prone type of coconut. A study conducted by Palomar et al. (1994) on the wood quality of San Ramon timber has shown that high values in all the mechanical properties relevant to timber quality. The form San Ramon is believed to be originated from Mindanao islands in the Philippines where frequent fluctuations in climatic conditions are experienced and as a result the cultivar may have accumulated favourable genes over a long period of adaptation (Santos et al., 1984). In a study 
carried out on 7 tall populations in the Philippines, Balingasa and Carpio (1983) reported that San Ramon had the lowest coefficient of variability for bunch characteristics. Having these outstanding beneficial characters, San Ramon has been used and also is being currently used for various crosses to transmit the drought tolerance nature and high copra outturn to the offspring.

A useful molecular marker technique in identification of different coconut types and their crosses should be based on a method that can be reliably reproduced in any laboratory. Out of many molecular marker methods, microsatellites (Simple Sequence Repeats or SSRs) (Powell et al., 1996) has been accepted as an identical tool for genotyping individuals and hybridity testing, particularly because they are reproducible and codominant in nature with an excellent ability in differentiating homozygotes from heterozygotes, in addition to its highly polymorphic and multiallelic nature coupled with simple to perform PCR based approach. However, the use of SSR is limited to a small number of crop species as the development of these markers for each crop species is too expensive. Despite this difficulty, substantial number of SSR primers for the PCR has been developed for coconut (Perera et al., 1999; Rivera et al., 1999; Teulat et al., 2000).

The only available coconuts in Sri Lanka are under two main varieties, Tall and Dwarf apart from the introduced type, San Ramon. Consequently, until now the crosses were made within those three types of coconut. The first introduction of San Ramon to Sri Lanka was made by a private grower and was planted at the Clovis Estate, North Western Province of Sri Lanka (CRI, 1987). A few seedlings arising from open pollinations from the Clovis introduction was planted at the Coconut Research Institute of Sri Lanka (CRISL) and these palms were used as parents to raise selfed progenies. Therefore, some palms, currently available in CRISL and also believed to be San Ramon, might not be pure San Ramon due to initially introduced open pollinated seedlings from Clovis. Under this confused state, it is worth to develop a DNA fingerprinting method to distinguish San Ramon from its crosses and also from Tall and Dwarf types to verify the identity of parents and progeny in breeding populations in the absence of clear morphological differences among them. In addition, misidentification of varieties in long term breeding trials may pose serious problems. Therefore, this study was carried out with an objective of developing a molecular finger printing method using already developed coconut SSR to distinguish pure San Ramon (SR) from Tall x San Ramon (TxSR) and Dwarf Green x San Ramon (DGxSR).

\section{Materials and methods}

\section{Genetic material}

A total of 77 individuals representing 3 coconut varieties, Tall, Dwarf and San Ramon (each variety was represented by 5 individuals) and 62 palms believed to be San Ramon were used in this study. DNA was extracted from each individual separately according to Doyle and Doyle (1990). Diluted DNA was quantified using standard $\lambda$ DNA in agarose gels. The DNA was further diluted to $10 \mathrm{ng} / \mu \mathrm{l}$ as working samples for microsatellite primers.

\section{Microsatellite (SSR) primers}

Ten coconut SSR primers, which had been identified as suitable primers to clearly distinguish Tall and Dwarf Green coconuts (Bandaranayake, 2002), tested on selected genetic material. All information on selected SSR primers is given in Table 1.

\section{PCR and gel electrophoresis}

PCR was carried out with each primer pair of $10 \mu \mathrm{l}$ reactions, which contain, $10 \mathrm{ng}$ genomic DNA, $10 \mu \mathrm{M}$ Forward primer, $10 \mu \mathrm{M}$ Reverse primer, $0.2 \mathrm{mM}$ deoxyribonucleotides, $1.5 \mathrm{mM}$ magnesium chloride, $1 \mathrm{x}$ PCR buffer and 1 unit of Taq DNA polymerase. Standard cycling conditions were: denature at $94^{\circ} \mathrm{C}$ for 1 min, annealing at optimum temperature for 1 min, extend at $72^{\circ} \mathrm{C}$ for $2 \mathrm{~min}$ and repeat this for 30 cycles. 
Polyacrylamide gel electrophoresis (PAGE) was used since it provided greater resolution than agarose gel electrophoresis in the analysis of closer alleles. Silver staining procedure (Bassam and Caetano-Anolles, 1993) was used for staining the polyacrylamide gels and alleles were scored under an UV transilluminator.

\section{Results and discussion}

At first, DNA of individual palms of 3 varieties was amplified with all 10 SSR primer pairs. All 5 individual palms under each variety were given the same alleles under each SSR primer except one individual of San Ramon. As a result, that individual San Ramon was discarded from our experiment and other individuals were bulked under each variety. These 3 bulks, Tall, Dwarf and San Ramon, were then used to represent each variety under 10 selected SSR primer pairs.

Of the 10 SSR primers used, only three, viz; CAC8, CNZ6 and CNZ44, showed clear polymorphic bands between the three varieties of coconut, Tall $\left(a_{1}\right)$, Dwarf $\left(a_{2}\right)$ and San Ramon $\left(a_{3}\right.$ or $\mathrm{a}_{3}$ and $\mathrm{a}_{4}$ ) (Table 2). These three SSR primers were then used to amplify the DNA of other palms, which were supposed to be San Ramon, and three pure varieties. Out of 62 palms, which were supposed to be San Ramon, only 52 showed either one or both San Ramon specific alleles as $\mathrm{a}_{3}$ or $\mathrm{a}_{4}$ or $\mathrm{a}_{3}$ and $\mathrm{a}_{4}$ under CAC8.

With CNZ6, only 27 individuals showed a San Ramon specific band, $a_{3}$. Figure 1 illustrates a sample of 19 individuals who were supposed to be San Ramon with 3 pure varieties [Tall (T), Dwarf (D) and San Ramon (SR)] on either side of the gel. The 3 alleles under Tall, Dwarf and San Ramon are much apart under CNZ6 and therefore, the scoring was very easy. It shows that 15 individuals out of 19 are SR except sample numbers 1, 2, 3 and 4. Sample numbers 1, 2 and 4 could be considered as DxSR hybrids while sample number 3 has not worked. These results indicate that the SSR primer CNZ6 can be successfully used to distinguish Tall, Dwarf and
San Ramon having presence of alleles $a_{1}, a_{2}$ and $a_{3}$ respectively. The presence of both $a_{2}$ and $a_{3}$ alleles in heterozygous state confirms the status of DxSR hybrid.

Only 35 individuals showed San Ramon specific allele $a_{3}$ in CNZ44 with a small shift in the size of the bands under 3 varieties. Figure 2 clearly demonstrates a gel showing the banding profile of a sample of individuals with CNZ44. It shows that 15 individuals out of 19 as SR, except the sample numbers 7 and 14 are TxSR hybrids while numbers 3 and 12 have not worked. Since the primer CNZ44 produces an exclusive band for SR $\left(\mathrm{a}_{3}\right)$ and different bands for Tall and Dwarf ( $a_{1}$ and $a_{2}$ respectively), sample numbers 7 and 14 could be confirmed as TxSR hybrids with the presence of both $\mathrm{a}_{1}$ and $\mathrm{a}_{3}$ bands. When we consider SSR primers CAC8 and CNZ6, all 27 individuals, which have shown San Ramon specific allele under CNZ6, were available under CAC8. Only 24 individuals out of 27, which have shown San Ramon specific alleles under CNZ6, were present under CNZ44. Considering CAC8 and CNZ44, the same 24 individuals have come up as pure San Ramon. Results are summarized in Table 3.

In view of a single primer, CAC8 has shown many individuals (52 out of 62) as San Ramon. However, CAC8 was not a reliable primer to score San Ramon since it has given 2 alleles for San Ramon and the presence of those 2 alleles was not consistent because some individuals have one allele, some have the other allele and some have both alleles. Accordingly, the individuals who had either one allele or both were scored as San Ramon. Therefore, the scoring was not too consistent.

Considering the primer pairs at a time, CAC8 and CNZ6, individuals identified as San Ramon under CNZ6 was a sub group under CAC8. In a similar way, the palms established as San Ramon with CNZ44 was a sub group with CAC8. Therefore, CAC8 could be excluded from this analysis since it was not an 
Table 1. Selected 10 SSR markers, their repeat motifs, annealing temperatures, and estimated fragment sizes according to Perera et al., (1999), Rivera et al., (1999) and Teulat et al., (2000)

\begin{tabular}{|l|l|c|c|}
\hline \multicolumn{1}{|c|}{ Locus } & \multicolumn{1}{|c|}{ Repeat motif } & \multicolumn{1}{|c|}{$\begin{array}{c}\text { Annealing } \\
\text { temperature }\left({ }^{0} \mathrm{C}\right)\end{array}$} & $\begin{array}{c}\text { Fragment size } \\
(\mathrm{bp})\end{array}$ \\
\hline CAC2 & $(\mathrm{CA})_{12}(\mathrm{AG})_{14}$ & 58 & 220 \\
$\mathrm{CAC6}$ & $(\mathrm{AG})_{14}(\mathrm{CA})_{9}$ & 58 & 158 \\
$\mathrm{CAC} 8$ & $(\mathrm{AG})_{10}(\mathrm{CA})_{9}$ & 58 & 190 \\
$\mathrm{CAC} 10$ & $(\mathrm{TA})_{6} \mathrm{CATA}(\mathrm{CA})_{11}(\mathrm{TA})_{8}$ & 58 & 198 \\
$\mathrm{CAC} 13$ & $(\mathrm{CA})_{9}(\mathrm{TA})_{5} \mathrm{~A}(\mathrm{TA})_{4}(\mathrm{CA})_{6}$ & 58 & 160 \\
$\mathrm{CAC} 23$ & $(\mathrm{CA})_{8}$ & 54 & 192 \\
$\mathrm{CNZ6}$ & $(\mathrm{CT})_{15}$ & 53 & 85 \\
$\mathrm{CNZ29}$ & $(\mathrm{GT})_{22}(\mathrm{GA})_{2} \mathrm{CA}(\mathrm{GA})_{11}$ & 51 & 135 \\
$\mathrm{CNZ40}$ & $(\mathrm{CT})_{20}$ & 53 & 151 \\
CNZ44 & $(\mathrm{GA})_{15}$ & 53 & 165 \\
\hline
\end{tabular}

Table 2. Ten selected primers and their alleles under each variety

\begin{tabular}{|l|c|c|c|}
\hline \multirow{2}{*}{ SSR primer } & \multicolumn{3}{|c|}{ Alleles under each variety (Different alleles were marked as } \\
\cline { 2 - 4 } & $\mathrm{a}_{1}, \mathrm{a}_{2}, \mathrm{a}_{3}$ and $\mathrm{a}_{4}$ under each SSR primer) \\
\hline CAC2 & Tall & Dwarf & San Ramon \\
CAC6 & $\mathrm{a}_{1}$ & $\mathrm{a}_{2}$ & $\mathrm{a}_{2}$ \\
CAC8 & $\mathrm{a}_{1}$ & $\mathrm{a}_{2}$ & $\mathrm{a}_{2}$ \\
CAC10 & $\mathrm{a}_{1}$ & $\mathrm{a}_{2}$ & $\mathrm{a}_{3}, \mathrm{a}_{4}$ \\
CAC13 & $\mathrm{a}_{1}, \mathrm{a}_{2}$ & $\mathrm{a}_{3}$ & $\mathrm{a}_{3}$ \\
CAC23 & $\mathrm{a}_{1}, \mathrm{a}_{2}$ & $\mathrm{a}_{2}$ & $\mathrm{a}_{1}, \mathrm{a}_{2}$ \\
CNZ6 & $\mathrm{a}_{1}$ & $\mathrm{a}_{2}$ & $\mathrm{a}_{2}$ \\
CNZ29 & $\mathrm{a}_{1}$ & $\mathrm{a}_{2}$ & $\mathrm{a}_{3}$ \\
CNZ40 & $\mathrm{a}_{1}, \mathrm{a}_{2}$ & $\mathrm{a}_{2}$ & $\mathrm{a}_{1}, \mathrm{a}_{2}$ \\
CNZ44 & $\mathrm{a}_{1}$ & $\mathrm{a}_{2}$ & $\mathrm{a}_{2}$ \\
\hline
\end{tabular}

Table 3. Number of individuals identified came up as San Ramon under a single primer and combinations of primers

\begin{tabular}{|c|c|c|}
\hline CAC8 & CNZ6 & CNZ44 \\
\hline 52 & 27 & 35 \\
\hline \multicolumn{2}{|c|}{24} \\
\hline \multicolumn{2}{|c|}{} \\
\hline
\end{tabular}




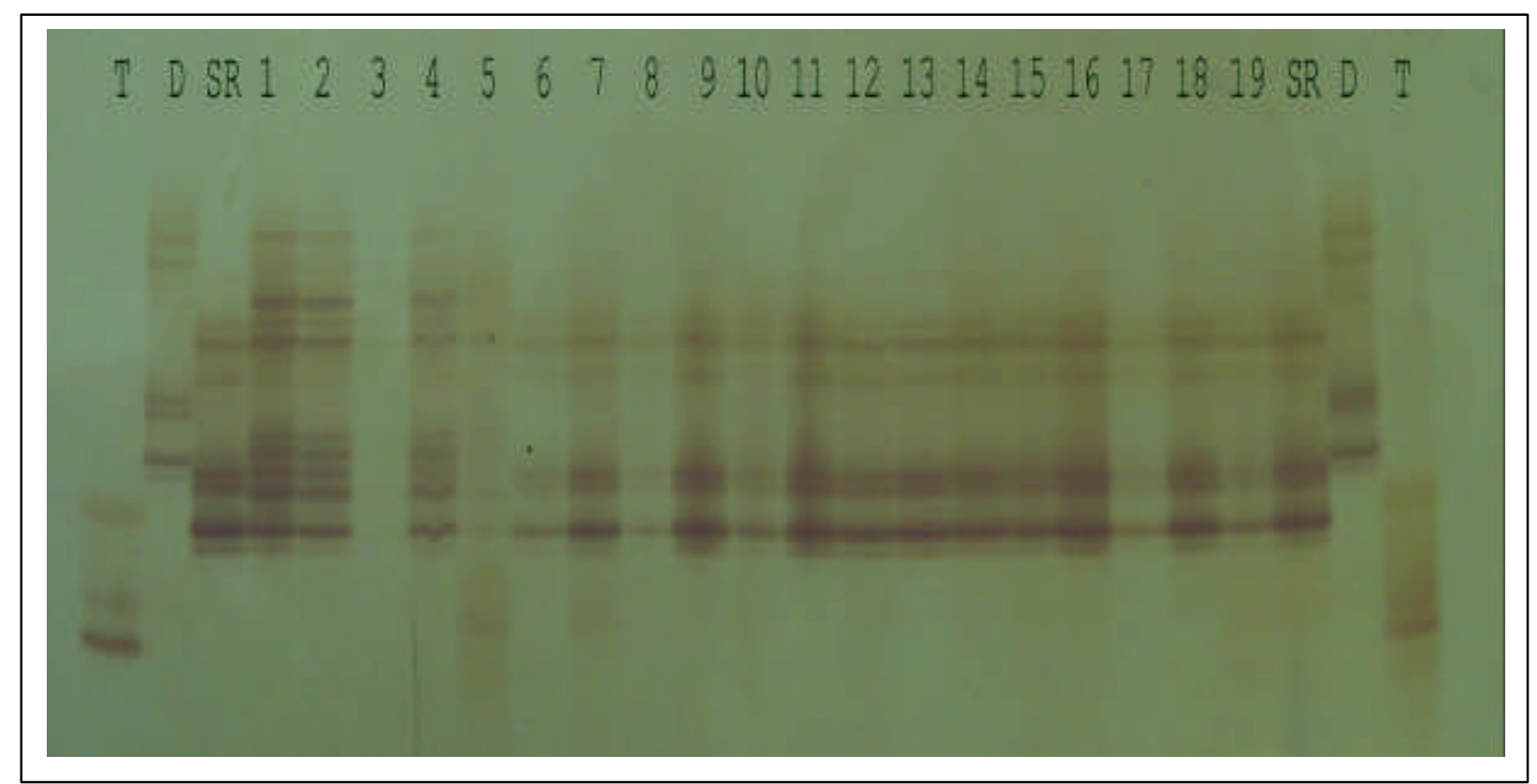

Figure 1. SSR banding profile of Tall (T), Dwarf (D), San Ramon (SR) with some individuals who supposed to be SR (from 1-19) with primer CNZ06

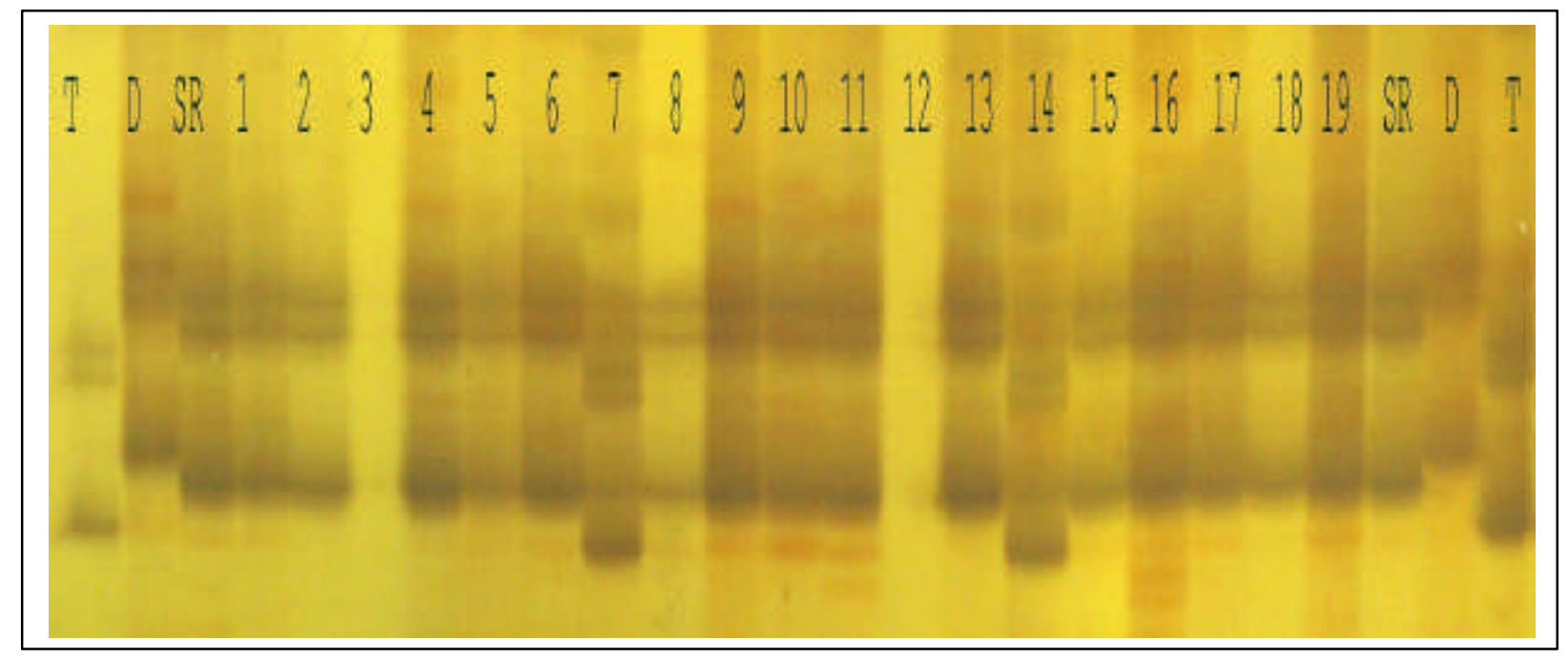

Figure 2. SSR banding profile of Tall (T), Dwarf (D), San Ramon (SR) with some individuals who supposed to be SR (from 1-19) with primer CNZ44 
appropriate primer to spot pure San Ramon. Thus, the results indicate the possibility of using 2 SSR primers, CNZ6 and CNZ44, as molecular markers to distinguish pure San Ramon from its crosses.

\section{References}

Balingasa, E.B. and Carpio, C.B. 1983. Genetic potential of some coconut populations of Philippines, pp. 71-81. In: Coconut Research and Development, N.M. Nayar (Ed.). Oxford IBH Publ. New Delhi, India.

Bandaranayake, C.K. 2002. Genome mapping of Arabidopsis thaliana and Cocos nucifera. $\mathrm{PhD}$ thesis. The University of Birmingham, UK, 227 pp.

Bassam, B.J. and Caetano-Anolles, G. 1993. Silver staining of DNA in polyacrylamide gels. Appl. Biochem. Biotech. 42: 181-188.

CRI, 1987. Report of Genetics and Plant Breeding Division In: Annual Report of the Coconut Research Institute for 1987, CRISL, pp. 51-107.

Dayrit, C.S. 2000. Coconut oil in health and disease: Its and monolaurin's potential as cure for HIV/AIDS. COCOTECH meeting 2000, Chennai, India.

Doyle, J.J. and Doyle, J.L. 1990. Isolation of plant DNA from fresh tissue. Focus 12: 1315.

Enig, M.G. 1999. Functional foods for health promotion: Physiologic considerations, Experimental Biology 1999, Renaissance Washington Hotel, USA.

Enig, M.G. 2001. Coconut: In support of good health in the $21^{\text {st }}$ century, APCC meeting 2001, Manila, Philippines.

Fernando, W.M.U. 1987. San Ramon, Big with Promise. Cocon. Bull. 4(1): 15.

Fernando, W.M.U. 1999. Genetic improvement of the coconut cultivar San Ramon. Cocos 13: 30-39.

Jayasekara, C., Ranasinghe, C.S. and Mathes, D.T. 1983. Screening for high yield and drought tolerance in coconut, pp. 209217. In: Coconut Research and Development, N.M. Nayar (Ed.). Oxford IBH Publ. New Delhi, India.

Palomar, R.N. and Fernandez, V.A. 1994. Variability of some mechanical properties of coconut wood. Philippine J. Cocon. Stud. 19: 5-14

Perera, L., Russell, J.R., Provan, J. and Powell, W. 1999. Identification and characterization of microsatellite loci in coconut (Cocos nucifera L.) and the analysis of coconut populations in Sri Lanka. Molecular Ecol. 8: 335-346

Powell, W., Machray, G.C. and Provan, J. 1996. Polymorphism as revealed by simple sequence repeats. Trends in Plant Science 1: $215-222$.

Ranasinghe, C.S. 1989. Physiological and biochemical characters of different varieties of coconut. In: Proc. Sri Lanka Assoc. for Advanc. Sci. 45: 55.

Rivera, R., Edwards, K.J., Barker, J.H.A., Arnold, G.M., Ayad, G., Hodgkin, T. and Karp, A. 1999. Isolation and characterization of polymorphic microsatellites in Cocos nucifera $\mathrm{L}$. Genome 42: 668-675.

Singh, T.N., Paleg, L.G. and Aspinall, D. 1973. Stress metabolism. 1. Nitrogen metabolism and growth in the barley plant during water stress. Australian J. Biol. Sci. 26: 65-76.

Santos, G.A., Cano, S.B., Cruz, B.V., Ilagan, M.C. and Bahala, R.T. 1984. Coconut germplasm collection in the Philippines. Philippine J. Cocon. Stud. 6: 1-9.

Teulat, B., Aldam, C., Trehin, R., Lebrun, P., Barker, J.H.A., Arnold, G.M., Karp, A., Baudouin, L. and Rognon, F. 2000. An analysis of genetic diversity in coconut (Cocos nucifera) populations from across the geographic range using sequencetagged microsatellites (SSRs) and AFLPs. Theor. Appl Genet. 100: 764-771. 